\title{
PENGARUH RASIO RIMPANG RUMPUT TEKI (Cyperus rotundus L.) DENGAN JAHE (Zingiber officinale) TERHADAP KAPASITAS ANTIOKSIDAN DAN MUTU WEDANG TEKI INSTAN
}

\author{
Nurwikan Sutralestari \\ Mazarina Devi \\ Soenar Soekopitojo
}

\begin{abstract}
Abstrak: Tujuan penelitian adalah untuk memperoleh proses pengolahan wedang teki instan, mengetahui kapasitas antioksidan serta mutu (rendemen, waktu rehidrasi, sifat fisik warna, dan uji hedonik) wedang teki instan dengan rasio rimpang rumput teki dan jahe berbeda. Jenis penelitian yang dilakukan merupakan penelitian eksperimen menggunakan Rancangan Acak Lengkap (RAL) dengan dua kali pengulangan. Data hasil analisis diuji menggunakan ANOVA (Analysis of Variances). Hasil penelitian yang diperoleh menunjukkan wedang teki instan dengan rasio rimpang rumput teki dan jahe yang berbeda berpengaruh terhadap kapasitas antioksidan, waktu rehidrasi, sifat fisik warna, serta uji hedonik rasa dan warna. Kapasitas antioksidan dan kesukaan rasa terbaik pada wedang teki instan dengan rasio rimpang rumput teki dan jahe 1 : $2 \frac{1}{2}$. Waktu rehidrasi tercepat, sifat fisik warna paling cerah dan kesukaan warna pada wedang teki instan dengan rasio rimpang rumput teki dan jahe $1: 1 \frac{1}{2}$.
\end{abstract}

Kata-kata Kunci: rimpang rumput teki, wedang teki instan, kapasitas antioksidan, mutu wedang

Abstract: Effect of Different Ratios of Nut Grass Rhizome (Cyperus Rotundus L.) and Ginger on the Antioxide Capacity and Quality of Instant Wedang Teki. This study aimed to describe the process to make an instant wedang teki, to determine the antioxidant capacity and quality (rendemen, rehydration time, physical properties of the color, and the hedonic test) of an instant wedang teki using different ratios of nut grass rhizome and ginger. This research is experimental research using a complete random design with two replications. The data is analyzed using ANOVA test. The finding shows that an instant wedang teki with different ratio of nut grass rhizome and ginger affects the antioxidant capacity, rehydration time, physical properties of color, and the hedonic test of taste and color. The highest antioxidant capacity and hedonic test of taste is obtained from the ratio of $1: 2 \frac{1}{2}$. The fastest of rehydration time, the brightest of physical properties and the highest of score hedonic test of color are resulted from the ratio of $1: 11 \frac{1}{2}$.

Keywords: nut grass rhizome, instant wedang teki, antioxidant capacity, quality of wedang

$\mathrm{R}$ umput teki (Cyperus rotundus L.) atau bisa disebut teki sering dianggap sebagai tanaman gulma oleh masya-

rakat, karena biasa tumbuh liar di lapangan berumput, pinggir jalan, tegalan, maupun lahan pertanian yang dapat

Nurwikan Sutralestari adalah Alumni Jurusan Teknologi Industri Universitas Negeri Malang. Email: mazarina.devi.ft@yahoo.com. Mazarina Devi dan Soenar Soekapitojo adalah Dosen Jurusan Teknologi Industri Universitas Negeri Malang. Alamat Kampus: Jl. Semarang No. 5 Malang 65145. 
mengganggu tanaman yang telah ditanam terlebih dahulu (Dalimartha, 2009). Penilaian masyarakat tentang rumput teki sebagai tanaman pengganggu membuat berbagai upaya masyarakat terutama petani berusaha untuk membasmi rumput teki, padahal rumput teki memiliki banyak khasiat bagi kesehatan dari bagian rimpangnya.

Khasiat dari rimpang rumput teki antara lain untuk menormalkan siklus haid, melancarkan vital energi yang tersumbat, tonik pada liver, meredakan nyeri (analgesik), dan antibakteri (Gupta, dkk., 2013). Sivapalan (2013) menarik kesimpulan rimpang rumput teki dapat digunakan sebagai astringent, diaphoretik, diuretik, analgesik, antispasmodik, aromatik, karminatif, antitusif, litolytik, sedatif, stimulan, antidiare, tonik, dan antibakteri. Dari hasil penelitian sebelumnya, rimpang atau umbi rumput teki memiliki beberapa kandungan penting seperti alkaloid, sineol, pinen, siperon, rotunol, siperenon, tanin, siperol, serta flavonoid (Murnah, 2012).

Salah satu jenis minuman yang banyak digemari oleh masyarakat Indonesia adalah wedang. (Pusat Bahasa, Tim Penyusun Kamus, 2005) menjelaskan wedang merupakan minuman dari bahan gula dan bahan lain seperti kopi, teh, jahe, dan sebagainya yang biasa diseduh dengan air panas, biasanya dapat menghangatkan tubuh. Rimpang rumput teki juga dapat diaplikasikan sebagai bahan dari wedang dengan bahan tambahan lain seperti jahe. Jenis jahe yang digunakan dalam penelitian adalah jahe gajah yang berfungsi untuk mengurangi rasa pahit dari rimpang rumput teki dan berkhasiat dalam menghangatkan tubuh. Selain itu, jahe memiliki beberapa kandungan penting antara lain minyak atsiri zingiberena, zingiberol, bisabolena, kurkumin, gingerol, filandrena, dan resinpahit (Wijoyo, 2008).
Penyajian makanan dan minuman saat ini semakin berkembang sesuai dengan kemajuan teknologi dan gaya hidup masyarakat modern. Gaya hidup masyarakat saat ini cenderung memilih hal-hal yang serba cepat atau instan. Saat ini banyak produk baik makanan maupun minuman yang instan yang diproduksi baik sebagai usaha rumah tangga ataupun sebagai suatu sebagai usaha industri.

Minuman instan dapat dibuat dengan menggunakan mesin maupun dengan cara manual yaitu melalui proses pengkristalan atau kristalisasi (Kristiani, 2013). Keuntungan dari penggunaan metode kristalisasi adalah dari segi biaya cukup murah, proses dapat dilakukan dengan cepat, dan serbuk yang dihasilkan banyak (Wahyuni, 2005). Kelebihan dari minuman instan yaitu daya tahan simpan produk yang lebih lama dibandingkan dengan produk yang dikemas dan disajikan dalam bentuk cairan atau siap saji. Hal tersebut disebabkan oleh kondisi produk yang sulit untuk dijadikan media tumbuh dan berkembangnya mikroba maupun jamur yang dapat membuat produk rusak (Kristiani, 2013). Minuman instan memiliki kadar air yang rendah sehingga tidak mudah terkotori dan terjangkit bibit penyakit (Kumalaningsih, dkk., 2005:3).

Pemanfaatan rimpang rumput teki yang masih kurang di lingkungan masyarakat membuat peluang yang cukup besar dalam mengenalkan bahwa rumput teki berkhasiat sebagai tanaman obat dan dapat dikonsumsi dalam bentuk minuman yaitu berupa wedang dengan dikemas dalam bentuk serbuk atau instan. Wedang instan yang terbuat dari rimpang rumput teki dan jahe diharapkan memiliki khasiat sebagai antioksidan bagi tubuh dan memiliki daya simpan yang lama. Penelitian ini bertujuan untuk mengkaji proses pengolahan wedang teki instan, mengetahui pengaruh rasio rimpang rumput teki 
dan jahe terhadap kapasitas antioksidan dan mutu wedang teki instan.

\section{METODE}

Penelitian yang dilakukan merupakan penelitian eksperimen dengan rancangan percobaan yang digunakan adalah Rancangan Acak Lengkap (RAL). Perlakuan dalam penelitian ini adalah perbedaan rasio dari rimpang rumput teki dan jahe yang digunakan pada wedang teki instan, untuk $\mathrm{A} 1$ = rasio rimpang rumput teki dan jahe $1 \frac{1 / 2}{2}: 1(\mathrm{~b} / \mathrm{b}), \mathrm{A} 2=$ rasio rimpang rumput teki dan jahe 2 : $1(\mathrm{~b} / \mathrm{b}), \mathrm{A} 3 \mathrm{=}$ rasio rimpang rumput teki dan jahe $2 \frac{1}{2}: 1(\mathrm{~b} / \mathrm{b})$. Ketiga perlakuan tersebut selanjutnya dianalisis kapasitas antioksidan dan mutu wedang teki instan yang meliputi rendemen, waktu rehidrasi, sifat fisik warna dan uji hedonik.

Bahan yang digunakan pada formula wedang teki instan adalah rimpang rumput teki, jahe gajah, gula kelapa, gula pasir, dan air. Alat yang digunakan untuk pembuatan wedang teki instan adalah timbangan, sendok, pisau, gelas ukur, kompor, ladle, ayakan, penyaring, blender, stockpot, work pan (penggorengan), dan mangkuk. Alat yang digunakan untuk analisis kimia antara lain tabung reaksi, kertas saring, oven, cawan petri, mikropipet, color reader, timbangan, stainless bowl, sendok, gelas ukur, gelas, dan stopwatch. Formula wedang teki instan dapat dilihat pada Tabel 1.

Pada wedang teki instan dilakukan pengamatan yang mencakup proses pengolahan, kapasitas antioksidan (metode DPPH), rendemen (metode perhitungan), waktu rehidrasi, sifat fisik warna (metode color reader), serta uji hedonik (penilaian kesukaan).

\section{HASIL}

Data yang diperoleh dari hasil uji kapasitas antioksidan wedang teki instan dengan rasio rimpang rumput teki dan jahe yang berbeda memiliki rerata data yang dapat dilihat pada Tabel 2.

Tabel 1. Formula Wedang Teki Instan

\begin{tabular}{lccrrr}
\hline \multicolumn{1}{c}{ Bahan } & A1 & A2 & A3 \\
& $(\mathbf{1} 1 / \mathbf{2}: \mathbf{1})$ & $(\mathbf{2}: \mathbf{1})$ & $(\mathbf{2} \mathbf{1} \mathbf{2} \mathbf{1})$ \\
\hline Rimpang rumput teki & 12,6 & $\mathrm{~g}$ & $14 \mathrm{~g}$ & 15 & $\mathrm{~g}$ \\
Jahe gajah & $8,4 \mathrm{~g}$ & $7 \mathrm{~g}$ & $6 \mathrm{~g}$ \\
Gula kelapa & 12 & $\mathrm{~g}$ & $12 \mathrm{~g}$ & $12 \mathrm{~g}$ \\
Gula pasir & 12 & $\mathrm{~g}$ & $12 \mathrm{~g}$ & $12 \mathrm{~g}$ \\
Air & $150 \mathrm{ml}$ & $150 \mathrm{ml}$ & $150 \mathrm{ml}$ \\
\hline
\end{tabular}

Tabel 2. Rerata Kapasitas $\left(\mathrm{IC}_{50}\right)$ Antioksidan Wedang Teki Instan

\begin{tabular}{ccccc}
\hline Kapasitas & \multirow{2}{*}{ Sampel } & \multicolumn{2}{c}{ Pengulangan } & \multirow{2}{*}{ Rerata } \\
\cline { 3 - 4 } Antioksidan & $\mathrm{A} 1$ & $\mathbf{1}$ & $\mathbf{2}$ & \\
\hline \multirow{2}{*}{$\mathrm{IC}_{50}(\mathrm{ppm})$} & $\mathrm{A} 2$ & 139,899 & 158,345 & 159,122 \\
& $\mathrm{~A} 3$ & 125,529 & 136,385 & 137,594 \\
& & & 123,632 & 124,581 \\
\hline
\end{tabular}

Tabel 3. Rerata Rendemen Wedang Teki Instan

\begin{tabular}{|c|c|c|c|c|}
\hline \multirow{2}{*}{ Mutu } & \multirow{2}{*}{ Sampel } & \multicolumn{2}{|c|}{ Pengulangan } & \multirow[t]{2}{*}{ Rerata } \\
\hline & & 1 & 2 & \\
\hline \multirow{3}{*}{ Rendemen (\%) } & A1 & 20,00 & 22,22 & 21,11 \\
\hline & A2 & 20,00 & 24,44 & 22,22 \\
\hline & A3 & 24,44 & 26,67 & 25,56 \\
\hline
\end{tabular}


Hasil analisis kapasitas antioksidan dari ketiga formula wedang teki instan menunjukkan bahwa rasio rimpang rumput teki dan jahe berpengaruh terhadap kapasitas antioksidan wedang teki instan. Wedang teki instan dengan rasio $2 \frac{1 / 2}{2}: 1$ memiliki kapasitas antioksidan yang lebih kuat dibandingkan dengan rasio $1 \frac{1 / 2}{2}$ : 1 dan 2 : 1 diduga karena banyaknya rimpang rumput teki yang lebih dominan daripada jahe gajah yang digunakan dalam wedang teki instan dengan rasio $2 \frac{1}{2} 2$ : 1. Rendemen wedang teki instan diperoleh rerata data yang dapat dilihat pada Tabel 3.

Data rendemen dari ketiga formula wedang teki instan yang telah dianalisis menunjukkan bahwa rasio rimpang rumput teki dan jahe yang berbeda tidak berpengaruh nyata terhadap rendemen wedang teki instan. Rendemen yang dihasilkan wedang teki instan dengan rasio rimpang rumput teki dan jahe yang berbeda memiliki nilai yang berkisar antara 21 hingga 25 persen. Ketiga formula wedang teki instan memiliki rendemen yang tidak berbeda nyata disebabkan berat awal dari ketiga sampel memiliki jumlah yang sama.
Berat awal wedang teki instan dihitung berdasarkan jumlah dari rimpang rumput teki, jahe, gula kelapa, dan gula pasir. Rasio jahe yang digunakan memiliki kandungan minyak atsiri yang berbeda namun karena jumlah kandungan minyak atsiri cenderung kecil maka rendemen dari ketiga wedang teki instan tidak berbeda secara signifikan. Komponen minyak atsiri pada jahe memiliki konsentrasi yang cenderung stabil yaitu berkisar antara 1-3\% (Widiyanti, 2009). Waktu rehidrasi wedang teki instan memiliki rerata data yang disajikan padaTabel 4 .

Hasil analisis waktu rehidrasi wedang teki instan menunjukkan bahwa dengan rasio rimpang rumput teki dan jahe yang berbeda mempengaruhi waktu rehidrasi wedang teki instan. Waktu rehidrasi tercepat dialami oleh wedang teki instan dengan rasio rimpang rumput teki dan jahe $1 \frac{1}{2}: 1$, yaitu dengan waktu 19 detik.

Hasil analisis warna tingkat kecerahan (L), tingkat kemerahan (a+), dan tingkat kekuningan $(\mathrm{b}+)$ wedang teki instan dengan rasio rimpang rumput teki dan jahe yang berbeda dapat dilihat pada Tabel 5. Analisis sifat fisik warna dari wedang teki instan menunjukkan bahwa

\section{Tabel 4. Rerata Waktu Rehidrasi Wedang Teki Instan}

\begin{tabular}{|c|c|c|c|c|}
\hline \multirow{2}{*}{ Mutu } & \multirow{2}{*}{ Sampel } & \multicolumn{2}{|c|}{ Pengulangan } & \multirow{2}{*}{ Rerata } \\
\hline & & 1 & 2 & \\
\hline \multirow{3}{*}{$\begin{array}{l}\text { Waktu Rehidrasi } \\
\quad \text { (detik) }\end{array}$} & A1 & 21 & 17 & 19 \\
\hline & $\mathrm{A} 2$ & 40 & 38 & 39 \\
\hline & A3 & 60 & 58 & 59 \\
\hline
\end{tabular}

Tabel 5. Rerata Warna Wedang Teki Instan

\begin{tabular}{ccrrr}
\hline \multirow{2}{*}{ Warna } & \multirow{2}{*}{ Sampel } & \multicolumn{2}{c}{ Pengulangan } & \multirow{2}{*}{ Rerata } \\
\cline { 3 - 4 } & & $\mathbf{1}$ & $\mathbf{2}$ & \\
\hline \multirow{2}{*}{$\mathrm{L}$} & $\mathrm{A} 1$ & 87,81 & 87,77 & 87,79 \\
& $\mathrm{~A} 2$ & 85,46 & 85,41 & 85,44 \\
& $\mathrm{~A} 3$ & 82,81 & 82,75 & 82,78 \\
\hline \multirow{3}{*}{$\mathrm{a}+$} & $\mathrm{A} 1$ & 7,00 & 7,04 & 7,02 \\
& $\mathrm{~A} 2$ & 7,69 & 7,52 & 7,61 \\
& $\mathrm{~A} 3$ & 7,75 & 7,64 & 7,70 \\
\hline \multirow{2}{*}{$\mathrm{b}+$} & $\mathrm{A} 1$ & 44,12 & 44,06 & 44,09 \\
& $\mathrm{~A} 2$ & 43,42 & 43,36 & 43,39 \\
& $\mathrm{~A} 3$ & 42,25 & 42,16 & 42,21 \\
\hline
\end{tabular}




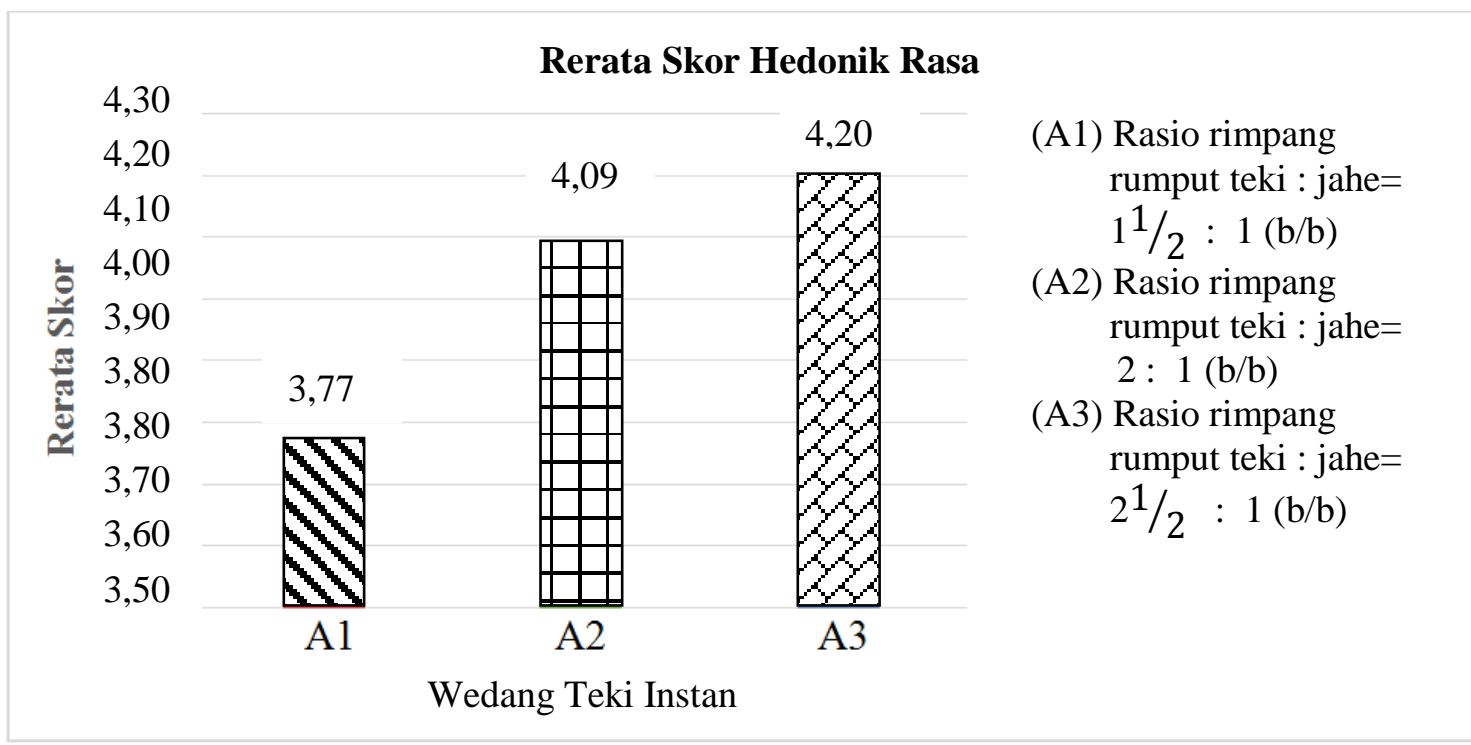

\section{Gambar 1. Rerata Skor Hedonik Rasa Wedang Teki Instan}

nilai tingkat kecerahan (L) dan tingkvat kekuningan $(b+)$ semakin kecil pada penggunaan rasio rimpang rumput teki yang semakin besar. Berbanding terbalik dengan nilai tingkat kemerahan $(\mathrm{a}+)$ yang memiliki nilai semakin besar pada wedang teki instan dengan rasio rimpang rumput teki yang semakin besar. Hal ini menunjukkan bahwa semakin banyak rimpang rumput teki yang digunakan maka warna wedang teki instan semakin gelap. Berdasarkan tingkat kecerahan (L), tingkat kekuningan $(\mathrm{b}+)$, dan tingkat kemerahan $(\mathrm{a}+)$ menunjukkan bahwa warna wedang teki instan yang paling cerah diperoleh dari wedang teki instan dengan rasio rimpang rumput teki dan jahe $1 \frac{1 / 2}{2}$ : 1.

Wedang teki instan untuk uji kesukaan rasa disajikan kepada panelis berupa wedang teki instan yang sudah diseduh. Uji kesukaan warna dan aroma dilakukan dengan memberikan tiga sampel serbuk wedang teki instan kepada panelis. Hasil rerata skor kesukaan panelis terhadap rasa wedang teki instan dapat dilihat pada Gambar 1.

Penilaian panelis berdasarkan kesukaan terhadap rasa wedang teki instan dengan rasio rimpang rumput teki dan jahe
$1 \frac{1}{2}: 1$ adalah biasa saja, rasio rimpang rumput teki dan jahe 2 : 1 cukup disukai, sedangkan untuk rasio rimpang rumput teki dan jahe 21/2: 1 cenderung disukai. Hal tersebut dikarenakan beberapa panelis menyatakan alasan bahwa rasa dari wedang teki instan dengan rasio rimpang rumput teki dan jahe $2 \frac{1 / 2}{2}: 1$ memiliki rasa rimpang rumput teki yang lebih tajam dan seimbang dengan rasa jahe, gula kelapa serta gula pasir. Hasil rerata skor kesukaan panelis terhadap warna wedang teki instan dapat dilihat pada Gambar 2.

Kesukaan panelis terhadap warna wedang teki instan dengan rasio rimpang rumput teki dan jahe $2 \frac{1}{2}: 1$ adalah cukup disukai, untuk wedang teki instan dengan rasio rimpang rumput teki dan jahe $2: 1$ cenderung disukai, dan wedang teki instan dengan rasio rimpang rumput teki dan jahe $1 \frac{1 / 2}{2}: 1$ adalah disukai.

Berdasarkan alasan kesukaan yang dinyatakan oleh panelis, warna wedang teki instan dengan rasio rimpang rumput teki dan jahe $2 \frac{1}{2}: 1$ dinilai terlalu gelap atau pekat. Penilaian yang hampir sama juga dilakukan oleh panelis terhadap warna wedang teki instan dengan rasio rimpang rumput teki dan jahe $2: 1$ yang dinilai sudah cukup terang jika dibanding- 


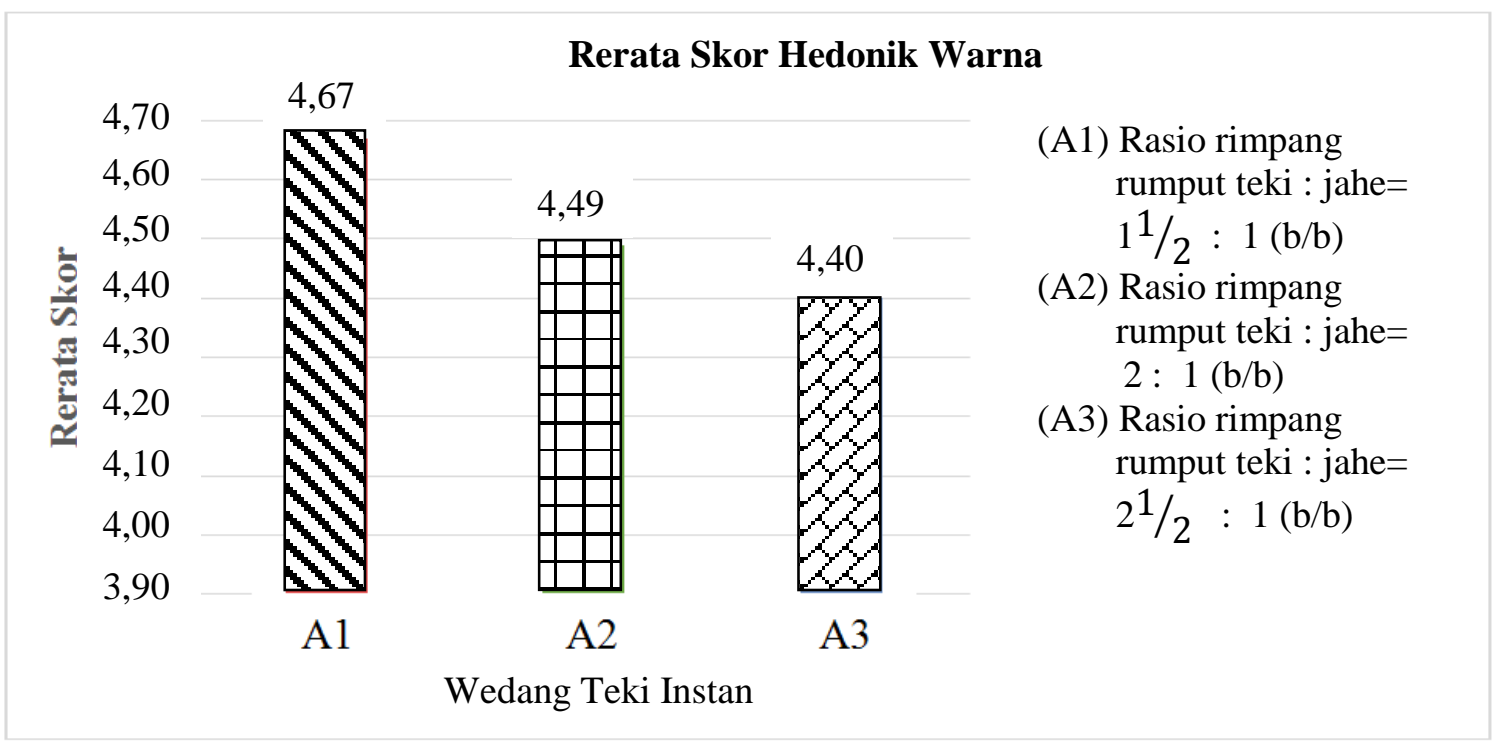

Gambar 2. Rerata Skor Hedonik Warna Wedang Teki Instan

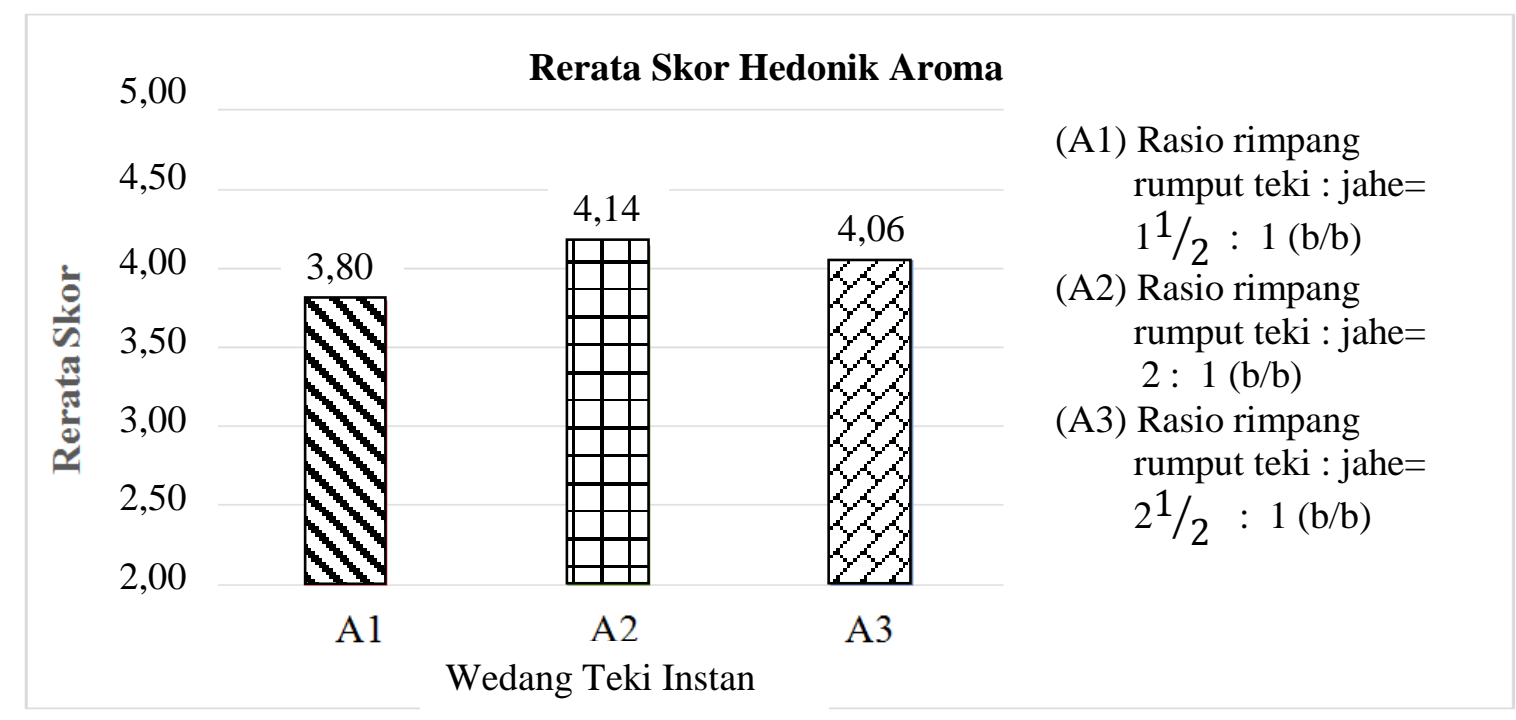

\section{Gambar 3. Rerata Skor Hedonik Aroma Wedang Teki Instan}

kan dengan rasio rimpang rumput teki dan jahe $2 \frac{1}{2}: 1$.

Panelis cenderung menyukai warna wedang teki instan dengan rasio rimpang rumput teki dan jahe 11/2: 1 karena memiliki warna kuning yang lebih terang dibandingkan dengan sampel wedang teki instan rasio lain. Warna kuning yang lebih pekat disebabkan kandungan senyawa antioksidan berupa tanin dan flavonoid yang terdapat pada wedang teki instan dengan rasio rimpang rumput teki dan jahe $2 \frac{1 / 2}{2}: 1$ lebih tinggi. Flavonoid dan tanin memiliki warna putih, kuning, hingga coklat terang (Ismarani, 2012). Hasil rerata skor kesukaan panelis terhadap warna wedang teki instan dapat dilihat pada Gambar 3.

Hasil data rerata skor kesukaan panelis terhadap aroma wedang teki instan dengan rasio rimpang rumput teki dan jahe $1 \frac{1}{2}$ : 1 sebesar 3,80 yaitu cukup suka. Rerata skor kesukaan panelis terhadap aroma wedang teki instan dengan rasio rimpang rumput teki dan jahe $2: 1$ sebesar 4,14 yaitu agak suka. Rerata skor 
kesukaan panelis terhadap aroma wedang teki instan dengan rasio rimpang rumput teki dan jahe 21/2: 1 sebesar 4,06 yaitu agak suka.

\section{PEMBAHASAN}

Proses pembuatan wedang teki instan menggunakan prinsip kristalisasi dengan prosedur yang dimodifikasi dari cara pembuatan dan formula terbaik yang diperoleh pada penelitian Anggraeni (2014) dan Septalina (2015). Modifikasi yang dilakukan pada cara pembuatan dan formula dari penelitian Anggraeni (2014) adalah penambahan jahe dan gula kelapa. Modifikasi dari penelitian Septalina (2015) dilakukan pada perubahan proses penghancuran jahe dan dilanjutkan dengan proses kristalisasi yang melibatkan sifat gula pasir. Kelebihan dari penggunaan metode kristalisasi adalah dari segi biaya cukup murah, proses dilakukan dengan cepat, dan serbuk yang dihasilkan banyak (Wahyuni, 2005). Diagram alir pembuatan wedang teki instan dapat dilihat pada Gambar 4.

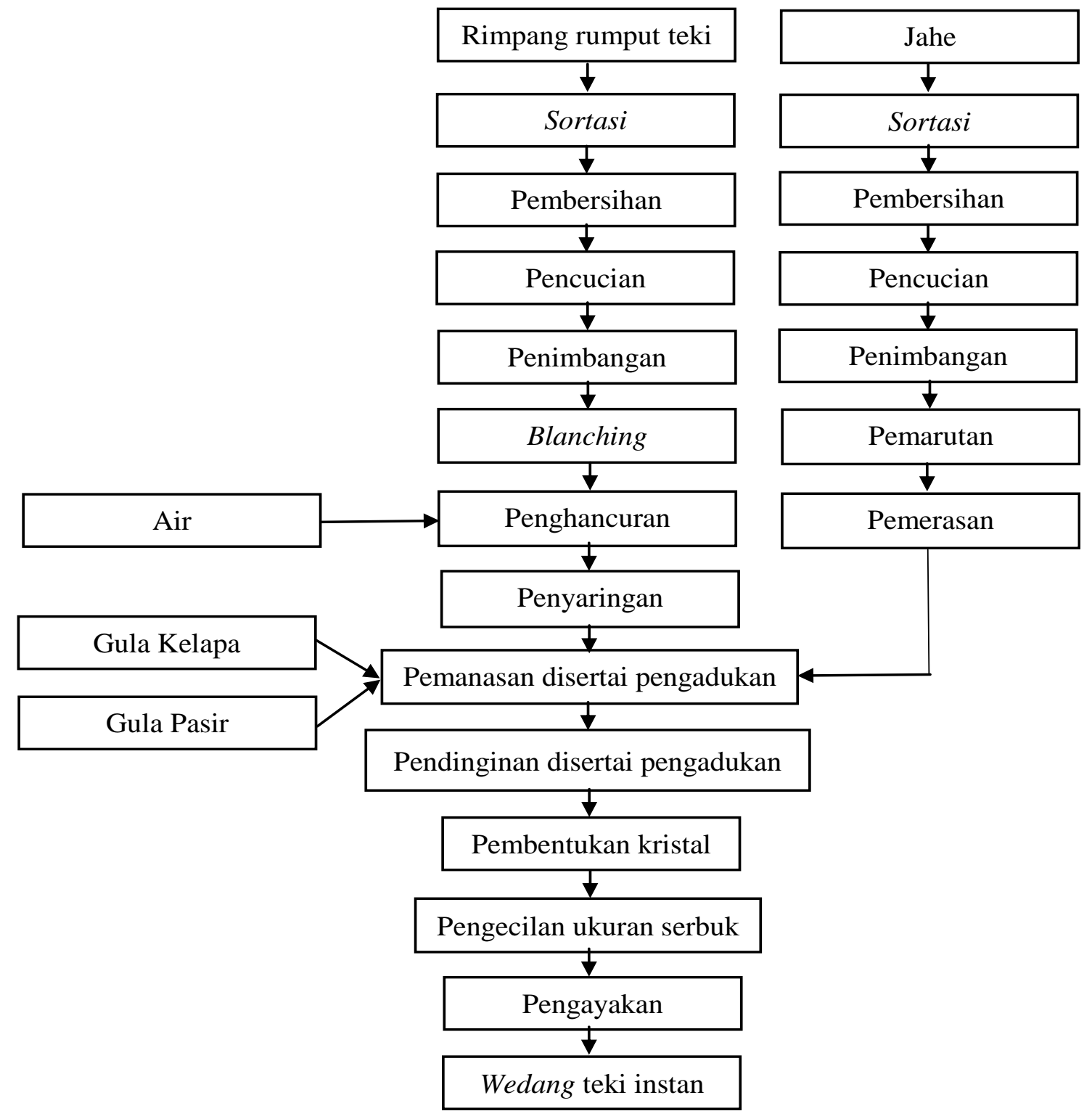

Gambar 4. Diagram Alir Pembuatan Wedang Teki Instan 
Penggunaan jahe pada wedang teki instan bertujuan untuk mengurangi rasa pahit yang ditimbulkan rimpang rumput teki. Jenis jahe yang digunakan adalah jahe gajah karena jahe gajah mempunyai kandungan gingerol yang paling rendah jika dibandingkan dengan jahe emprit dan jahe merah. Kandungan gingerol jahe mulai dari yang terbesar hingga terkecil adalah jahe emprit, jahe merah, dan jahe gajah (Fathona, 2011). Pemilihan jahe gajah dengan kandungan gingerol yang rendah agar saat proses kristalisasi dalam pembuatan wedang teki instan tidak mengubah gingerol menjadi shogaol yang menyebabkan rasa wedang teki lebih pedas dibandingkan sebelum mengalami proses kristalisasi. Senyawa utama dari jahe adalah gingerol yang memiliki sifat tidak stabil terhadap panas dan pada suhu tinggi akan berubah menjadi shogaol. Shogaol lebih pedas dibandingkan dengan gingerol (Mishra, 2009).

Proses penghancuran jahe pada wedang teki instan dilakukan dengan cara diparut agar komponen minyak atsiri dan gingerol yang dihasilkan lebih terekstrak dibandingkan dengan cara diblender dengan penambahan air. Proses pengolahan wedang teki untuk menjadi serbuk membutuhkan waktu yang lama sehingga dibutuhkan ekstrak dari jahe yang cukup banyak agar minyak atsiri yang dihasilkan tidak menguap secara keseluruhan karena proses pemanasan yang lama. Minyak atsiri adalah minyak yang mudah menguap dan memberikan bau yang khas (Koensoemardiyah, 2010).

Penggunaan gula kelapa dalam pembuatan wedang teki instan bertujuan untuk menambah aroma dan sebagai bahan pemanis selain gula pasir yang memiliki kandungan gula (sukrosa) lebih tinggi. Kandungan gula (sukrosa) pada gula kelapa lebih rendah jika dibandingkan dengan gula pasir sehingga baik untuk penderita diabetes (Sihombing, 2013). Gula kelapa dan gula pasir yang digunakan pada formula wedang teki instan memiliki berat yang sama besarnya. Formula wedang teki instan tidak menggunakan gula kelapa sepenuhnya disebabkan perlunya sifat gula pasir dalam proses kristalisasi.

Proses kristalisasi dalam pembuatan minuman instan melibatkan sifat gula pasir yang dapat kembali membentuk kristal setelah dilarutkan (Anggraeni, 2014). Penggunaan gula kelapa pada wedang teki instan berpengaruh terhadap waktu pembentukan kristal yaitu \pm 20 menit, lebih lama dibandingkan dengan penggunaan gula pasir secara keseluruhan yang hanya membutuhkan waktu \pm 10 menit (Anggraeni, 2014). Hal tersebut terjadi diduga karena adanya komponen lain selain sukrosa atau gula invert pada gula kelapa. Jenis gula yang menyusun gula kelapa antara lain sukrosa, fruktosa, glukosa, dan maltosa. Adanya gula invert seperti glukosa dan fruktosa dalam larutan berpengaruh terhadap kecepatan pembentukan kristal (Geary, 2008). Komponen dari gula pasir hampir secara keseluruhan adalah sukrosa sehingga tidak banyak mengandung gula invert (Setiyoningrum, 2011). Bennion dan Scheule (2004) menyimpulkan proses kristalisasi campuran gula akan lebih mudah dikontrol apabila campuran gula tidak mengandung gula invert.

Senyawa antioksidan yang terdapat pada rimpang rumput teki lebih banyak dan beragam dibandingkan dengan jahe, sehingga dengan semakin bertambah banyak rasio rimpang rumput teki yang digunakan pada wedang teki instan, maka semakin kuat kapasitas antioksidan dari wedang teki instan.

Rimpang rumput teki mengandung banyak senyawa antioksidan antara lain $\beta$-sitosterol, cyperene, cyperol, flavonoid, sesquiterpenoid, asam askorbat, dan polifenol (Pal dan Dutta, 2006; Yazdanparast dan Ardestani, 2007). Kandungan lain dari rimpang rumput teki adalah alkaloid, 
triterpen, minyak atsiri, serta karbohidrat (Susianti, 2010). Rimpang rumput teki mengandung alkaloid sebanyak 0,30$1,00 \%$, minyak atsiri sebanyak 0,30 $1,00 \%$, flavonoid sebanyak $1,00-3,00 \%$, serta tanin sebanyak 6,50\% (Lawal dan Adebola, 2009; Murnah, 2012). Senyawa antioksidan yang terdapat pada jahe adalah minyak atsiri dan gingerol yang merupakan senyawa oleoresin (Wijoyo, 2008). Kandungan minyak atsiri pada jahe sebanyak 1,00-3,00\%, sedangkan gingerol sebanyak 0,50-2,50\% (Widiyanti, 2009; Fathona, 2011). Minyak atsiri adalah minyak yang mudah menguap dan memberikan bau khas jahe (Koensoemardiyah, 2010). Hal tersebut menyebabkan kapasitas antioksidan yang dihasilkan oleh jahe sangat berkurang ketika dilakukan pemasakan cukup lama yang membuat kadar air berkurang melalui proses penguapan.

Semakin bertambah besar rasio rimpang rumput teki yang digunakan, maka semakin lama waktu yang dibutuhkan serbuk wedang teki instan untuk larut sempurna dalam air. Hal ini dapat terjadi diduga disebabkan oleh adanya kandungan tanin dan alkaloid yang terdapat pada rimpang rumput teki. Semakin murni dan banyak kandungan tanin pada suatu bahan makanan, maka semakin berkurang kelarutannya dalam air (Sudjadi, 2010). Alkaloid biasanya tidak berwarna, mempunyai rasa pahit dan sulit larut dalam air (Mutiatikum, dkk., 2010). Sehingga semakin besar rasio rimpang rumput teki yang digunakan pada wedang teki instan maka semakin banyak kandungan tanin di dalamnya dan menjadikan serbuk membutuhkan waktu yang lama untuk larut secara sempurna di dalam air.

Berdasarkan hasil analisis waktu rehidrasi, ketiga formula wedang teki instan dengan rasio rimpang rumput teki dan jahe yang berbeda dapat dikatakan sebagai minuman dengan penyajian cepat (instan) karena memiliki waktu rehidrasi kurang dari 1 menit. Waktu rehidrasi atau waktu larut yang baik untuk minuman instan berupa serbuk adalah berkisar antara 1 menit (Diniari, 2012). Semakin cepat waktu rehidrasi yang diperoleh, maka semakin baik pula mutu produk minuman instan yang dihasilkan (Pentury, dkk., 2013). Hal ini juga diterapkan pada semakin cepat serbuk wedang teki instan terdispersi sempurna (larut) dalam air, maka semakin baik mutu wedang teki instan tersebut.

Wedang teki instan dengan rasio rimpang rumput teki dan jahe $1 \frac{1}{2}: 1$ memiliki rasa rimpang teki yang kurang kuat dan rasa pedas dari jahe lebih terasa sehingga panelis kurang menyukai wedang teki instan dengan formula tersebut. Senyawa utama dari jahe adalah gingerol yang memiliki sifat tidak stabil terhadap panas dan pada suhu tinggi akan berubah menjadi shogaol. Shogaol lebih pedas dibandingkan dengan gingerol (Mishra, 2009).

Warna wedang teki instan semakin berwarna gelap dengan penggunaan rasio rimpang rumput teki yang semakin besar dipengaruhi oleh kandungan tanin dan flavonoid yang terdapat pada rimpang rumput teki. Flavonoid memiliki warna putih hingga kuning, sedangkan warna tanin adalah putih kekuning-kuningan sampai coklat terang (Winarno, 2008). Warna tanin akan menjadi gelap apabila terkena cahaya langsung atau dibiarkan di udara terbuka (Ismarani, 2012). Hal tersebut diduga menyebabkan semakin besar rasio rimpang rumput teki yang digunakan, maka semakin bertambah kandungan tanin dan flavonoid yang membuat warna wedang teki instan semakin gelap.

Aroma yang ditimbulkan wedang teki instan diperoleh dari rimpang rumput teki, jahe, dan gula kelapa. Senyawa yang menimbulkan aroma dari rimpang rumput teki dan jahe adalah minyak atsiri. Minyak atsiri pada rimpang rumput teki 
berkisar $0,45-1 \%$, pada jahe kandungan minyak atsiri berkisar 1-3\% (Raj, dkk., 2012), (Widiyanti, 2009). Proses pembuatan wedang teki instan yang dilakukan dengan metode kristalisasi menyebabkan aroma khas rimpang rumput teki, jahe, dan gula kelapa cenderung berkurang ketika dilakukan proses pemasakan yang membutuhkan waktu cukup lama. Minyak atsiri adalah minyak yang mudah menguap dan memberikan bau khas (Koensoemardiyah, 2010). Hal tersebut menyebabkan tidak terdapat pengaruh yang nyata pada kesukaan panelis terhadap aroma wedang teki instan dengan rasio rimpang rumput teki yang berbeda.

\section{SIMPULAN DAN SARAN}

Hasil penelitian yang diperoleh menunjukkan bahwa tahapan dalam proses pembuatan wedang teki instan terdiri dari pemilihan bahan (sortasi), pembersihan bahan, pencucian, penimbangan bahan, blansir, penghancuran dan pemarutan, pemerasan dan penyaringan, proses pemasakan, pengecilan ukuran serbuk, serta pengayakan. Wedang teki instan dengan rasio rimpang rumput teki dan jahe yang berbeda berpengaruh terhadap kapasitas antioksidan, waktu rehidrasi, sifat fisik warna, serta uji hedonik rasa dan warna.

Kapasitas antioksidan tertinggi diperoleh dari wedang teki instan dengan rasio rimpang rumput teki dan jahe 1 : $2 \frac{1}{2}$. Waktu rehidrasi tercepat diperoleh dari wedang teki instan dengan rasio rimpang rumput teki dan jahe $1: 1 \frac{1}{2}$. Sifat fisik warna paling cerah diperoleh dari wedang teki instan dengan rasio rimpang rumput teki dan jahe $1: 1 \frac{1}{2}$. Skor uji hedonik rasa tertinggi diperoleh dari wedang teki instan dengan rasio rimpang rumput teki dan jahe $1: 2 \frac{1}{2}$. Skor uji hedonik warna tertinggi diperoleh dari wedang teki instan dengan rasio rimpang rumput teki dan jahe $1: 1 \frac{1}{2}$.
Berdasarkan hasil penelitian tentang kapasitas antioksidan dan mutu wedang teki instan, dapat disarankan bagi peneliti lain melakukan pengujian kandungan nutrisi secara lengkap pada wedang teki instan. Perlu juga dilakukan pembuatan kemasan wedang teki instan agar dapat disimpan untuk jangka panjang.

\section{DAFTAR RUJUKAN}

Anggraeni, F. 2014. Kajian Mutu Minuman Instan Rimpang Rumput Teki (Cyperus rotundus L.) sebagai $M i$ numan Fungsional. Skripsi tidak diterbitkan. Malang: Universitas Negeri Malang.

Bennion, M. \& Scheule, B. 2004. Introductory Foods, $13^{\text {th }}$ Edition. Amerika: Prentice Hall.

Dalimartha, S. 2009. Atlas Tumbuhan Obat Indonesia Jilid I. Jakarta: Trubus Agriwidya.

Diniari, A. 2012. Peningkatan Mutu dan Penerapan Cara Produksi Pangan yang Baik pada Industri Rumah Tangga Pangan Minuman Jahe Merah Instan di Desa Benteng, Ciampea, Bogor. Skripsi tidak diterbitkan. Bogor: Institut Pertanian Bogor.

Fathona, D. 2011. Kandungan Gingerol dan Shogaol, Intensitas Kepedasan dan Penerimaan Panelis terhadap Oleoresin Jahe Gajah (Zingiber officinale var. Roscoe), Jahe Emprit (Zingiber officinale var. Amarum), dan Jahe Merah (Zingiber officinale var. Rubrum). Skripsi tidak diterbitkan. Bogor: Institut Pertanian Bogor.

Geary, P.M. 2008. The Co-Crystallisation of Sugars by the Supersaturation Process. Doctural Thesis. Inggris: University of Hull.

Gupta, M., Banerjee, D., \& Mukherjee, A. 2013. Studies of Anti Inflammatory, Antipyretic and Analgesic Effects of Aqueous Extract of Traditional Herbal Drug on Rodents. In- 
ternational Research Journal of Pharmacy, 4(3): 113-120. doi:10. 7897/2230-8407.04321.

Ismarani. 2012. Potensi Senyawa Tannin dalam Menunjang Produksi Ramah Lingkungan. Jurnal Agribisnis dan Pengembangan Wilayah, 3(2): 4655.

Koensoemardiyah, S. 2010. A to Z Minyak Atsiri untuk Industri Makanan, Kosmetik, dan Aromaterapi. Yogyakarta: Andi Offset.

Kristiani, B.R. 2013. Kualitas Minuman Serbuk Effervescent Serai (Cymbopogon nardus (L.) Rendle) dengan Variasi Konsentrasi Asam Sitrat dan Na-Bikarbonat. Skripsi tidak diterbitkan. Yogyakarta: Universitas Atmajaya Yogyakarta.

Kumalaningsih, S., Suprayogi, \& Yudha, B.M.W. 2005. Membuat Makanan Siap Saji. Surabaya: Trubus Agrisarana.

Lawal, O.A. \& Adebola, O. 2009. Chemical Composition of The Essential Oils of Cyperus rotundus L. from South Africa. Journal Molecules, (14): 2909-2917.

Mishra, P. 2009. Isolasi Karakterisasi Spektroskopi dan Pemodelan Molekular Campuran Curcuma Longa, Jahe dan Biji Fenugreek. India: Departemen Kimia University of Delhi.

Murnah. 2012. Kajian Spektra Infra Merah dan UV Minyak Atsiri dari Umbi Teki (Cyperus rotundus Linn.). Media Medika Indonesiana, 46(1): 44-50.

Mutiatikum, D., Sukmayati, A., \& Yun, A. 2010. Standardisasi Simplisia dari Buah Miana (Plectranthus seutellaroides (L) R. Btlz) yang Berasal dari Tiga Tempat Tumbuh Menado, Kupang dan Papua. Jurnal Penelitian Kesehatan, 38(1): 1-16.

Pal, D.K. \& Dutta, S. 2006. Evaluation of the Antioxidant Activity of the Roots and Rhizomes of Cyperus ro- tundus L. Indian Journal of Pharmaceutical Sciences, 68(2): 256-258.

Pentury, M.H., Nursyam, H., Harahap, N., \& Soemarno. 2013. Karakterisasi Maltodekstrin dari Pati Hipokotil Mangrove (Bruguiera gymnorrhiza) menggunakan Beberapa Metode Hidrolisis Enzim. Indonesia Green Technology Journal, 2(1): 53-60.

Pusat Bahasa, Tim Penyusun Kamus. 2005. Kamus Besar Bahasa Indonesia. Jakarta: Balai Pustaka.

Raj, C.A., Ragavendran, P., Sophia, D., Rathi, M.A., Gopalakrishnan, V.K., 2012. Evaluation of in Vitro Antioxidant and Anticancer Activity of Alpinia Purpurata. Chinese Journal of Natural Medicines, 10 (10): 263268, doi: 10.1016/S1875-5364(12) 60053-3.

Septalina, T. 2015. Pengaruh Rasio Rimpang Rumput Teki (Cyperus rotundus L.) dan Jahe terhadap Mutu Minuman Fungsional "Wedang Teki". Skripsi tidak diterbitkan. Malang: Universitas Negeri Malang.

Setiyoningrum, P. 2011. Pembuatan Coro Instan Minuman Khas Pati Jawa Tengah. Skripsi tidak diterbitkan. Bogor: Institut Pertanian Bogor.

Sihombing, E.S.Y. 2013. Analisa Kandungan Rhodamin B dan Formalin pada Gula Merah serta Pengetahuan dan Sikap Pedagang di Pasar Tradisional Kecamatan Medan Baru Tahun 2013. Skripsi tidak diterbitkan. Medan: Universitas Sumatera Utara.

Sivapalan, S.R. 2013. Medicinal uses and Pharmacological activities of Cyperus rotundus Linn - A Review. International Journal of Scientific and Research Publications, 3(5): 1-8.

Sudjadi. 2010. Kimia Farmasi Analisis. Yogyakarta: Pustaka Pelajar.

Susianti. 2010. Pengaruh Ekstrak Kloroform Umbi Rumput Teki (Cyperus rotundus L.) terhadap Ekspresi Pro- 
tein BCL-2 pada Sel Hela. Jurnal Sains MIPA, 16(1): 1-7.

Wahyuni, N. 2005. Karakteristik Kimia dan Organoleptik Minuman Instan Madu Bubuk dengan Penambahan Kerabang Telur sebagai Sumber Kalsium. Skripsi tidak diterbitkan. Bogor: Institut Pertanian Bogor.

Widiyanti, R.K. 2009. Analisis Kandungan Fenol Total Jahe (Zingiber officinale Roscoe) secara In Vitro. Skripsi tidak diterbitkan. Jakarta: Universitas Indonesia.
Wijoyo, P.M. 2008. Sehat dengan Tanaman Obat. Jakarta: Bee Media Indonesia.

Winarno, F.G. 2008. Kimia Pangan dan Gizi. Jakarta: PT. Gramedia Pustaka Utama.

Yazdanparast, R. \& Ardestani, A. 2007. In vitro Antioxidant and Free Radical Scavenging Activity of Cyperus Rotundus. J. Med. Food, 10(4): 667674. 